\title{
Did the Introduction of Securities Margin Trading Decrease China's A-Share Market Volatility?
}

\author{
Maoguo $\mathrm{Wu}^{1}$, Hanyang Zhang ${ }^{1} \&$ Kwok-Leung $\mathrm{Tam}^{2}$ \\ ${ }^{1}$ SHU-UTS SILC Business School, Shanghai University, Shanghai, China \\ ${ }^{2}$ INSEARCH, University of Technology Sydney, Australia \\ Correspondence: Hanyang Zhang, SHU-UTS SILC Business School, Shanghai University, 20 Chengzhong Road, \\ Jiading District, Shanghai 201899, China. Tel: 86-131-2057-0087.
}

Received: June 15, 2017

Accepted: July 4, 2017

Online Published: July 7, 2017

doi:10.5430/ijfr.v8n3p135

URL: https://doi.org/10.5430/ijfr.v8n3p135

\begin{abstract}
Securities margin trading is a form of credit trading that is used extensively in mature securities markets. With the rapid development of its securities market, China introduced securities margin trading to its A-share market on $31^{\text {st }}$ March 2010 for the purpose of reducing A-share market volatility. Owing to the fact that the introduction of securities margin trading in 2010 only applied to part of the A-share transaction targets, it can be treated as a natural experiment. This paper uses difference-in-differences analysis to investigate whether the introduction of securities margin trading in 2010 decreased China's A-share market volatility. By selecting 50 underlying stocks of securities margin trading as a 'treatment group' and 50 non-underlying stocks as a 'control group', this paper utilizes a panel dataset comprising 100 stocks for the period 31 ${ }^{\text {st }}$ March $2009-31^{\text {st }}$ March 2011. Results indicate that the introduction of securities margin trading in 2010 significantly decreased China's A-share market volatility. In conclusion, this paper recommends that China reduces the barriers and transaction costs of securities margin trading, extends the supply of underlying stocks for securities lending, and enhances the capital supply of margin trading.
\end{abstract}

Keywords: securities margin trading, China's A-Shares, volatility, difference-in-differences

\section{Introduction}

Securities margin trading, also known as margin trading and securities lending, allows investors to buy or sell securities with borrowed money or securities from the stock exchange's member securities firms by pledging collateral to them (Shenzhen Stock Exchange n.d.). Since its creation over 300 years ago, securities margin trading has gradually become an indispensable part of mature securities markets. It is reported that securities margin trading comprises approximately $20 \%$ of the total volume of securities trading in both USA and Japan. In Taiwan, the proportion is as high as $40 \%$ or more. Its rapid development indicates that securities margin trading has become an indispensable driving force in the development of capital markets.

To parallel the national strategy of reform and external expansion and to meet the demands of economic development, China established the Shanghai Stock Exchange (SHSE) in 1990 and the Shenzhen Stock Exchange (SZSE) in 1991. China's stock market has grown substantially over the last 20 years. According to the World Federation of Exchanges, the total market capitalization of both the SHSE and the SZSE reached \$10 trillion in June 2015, which represents approximately $10 \%$ of global stock market capitalization (CNN Money 2015). However, the Chinese stock market has also exhibited a series of problems during this rapid expansion. Dramatic fluctuations were induced by strict investment constraints, limited transaction types, investors' irrational behavior and other factors. To resolve these problems, China unveiled a series of reforms related to the securities transaction system. For instance, it amended the Securities Act in 2001, launched the New Third Board in 2001, and introduced the innovative business of stock index futures and securities margin trading in 2010.

Among these reforms, the introduction of securities margin trading is considered to be a milestone in reducing stock price volatility and stabilizing the stock market. This is because, besides improving the elasticity of market demand and supply, it can also enhance market liquidity (Xu \& Chen 2012). Nevertheless, securities margin trading also has negative impacts on stock market volatility. Specifically, it might cause higher stock price fluctuations as it enlarges stock supply and demand. Presently, China has three stock exchanges: the SHSE and the SZSE, located in mainland 
China, and the Hong Kong Stock Exchange (HKSE), located in Hong Kong. Shares listed on one of China's stock exchanges can be classified as A-shares, B-shares or H-shares in terms of the currency in which they are denominated and the stock exchange on which they are listed. A-shares are denominated in renminbi (RMB) and listed on the SHSE or the SZSE. B-shares are denominated in US dollars (USD) and listed on the SHSE, or denominated in Hong Kong dollars (HKD) and listed on the SZSE. H-shares are denominated in Hong Kong dollars and listed on the HKSE (Xu \& Chen 2012). Correspondingly, the Chinese stock market comprises A-share, B-share and $\mathrm{H}$-share markets. According to information issued by the SHSE and the SZSE, until $22^{\text {nd }}$ October 2015, there were 2,780 kinds of A-shares in the A-share market and 101 kinds of B-shares in the B-share market. Moreover, the total value of the A-share market is RMB 34 trillion, whereas the value of the B-share market is only RMB 0.2 trillion. Did the introduction of securities margin trading in 2010 decrease China's A-share market volatility? This is a crucial question that China should consider, especially given that China endeavors to improve the system of securities margin trading and promote the healthy development of its stock market. A great deal of research pertains to this issue; however, very few studies have conducted a difference-in-differences (DID) analysis. As the business of securities margin trading, introduced in 2010, only selects some A-shares as transaction targets, this paper treats it as a natural experiment and attempts to investigate the abovementioned question using DID analysis. Empirical results indicate that the introduction of securities margin trading in 2010 significantly decreased China's A-share market volatility. Policy recommendations regarding China's securities market regulation are suggested accordingly.

The remaining part of this paper is organized as follows: Section 2 introduces the institutional background. Sections 3 reviews related literature. Section 4 is devoted to research methodology. Section 5 introduces the data. Section 6 presents the empirical results. Section 7 concludes the paper.

\section{Institutional Background}

The development of China's securities market has been stagnant for a long time. The SHSE and the SZSE initially prohibited securities margin trading to control risk. In 1999, the Securities Law of China was legislated, which stipulated that no securities company is allowed to engage in securities margin trading. Along with the improvement of the securities market environment and the constant strengthening of securities market regulation, the China Securities Regulatory Commission (CSRC) announced a pilot program of securities margin trading in 2008. However, the 2008 global financial crisis delayed the development of securities margin trading in China. On $31^{\text {st }}$ March 2011, the CSRC formally launched securities margin trading in the A-share market. However, at that time, only six securities companies were allowed to develop securities margin trading and the first batch of stocks numbered only 90, of which 50 were from the SHSE 50 Index and 40 were from the SZSE Composite Index (Xu \& Chen 2012). During the ensuing years, the CSRC increased the quantity of securities margin trading stocks to 278 in November 2011, 500 in January 2013, and 700 in September 2013. In September 2014, the figure reached 900, which constituted one-third of the total number of A-shares. The quantity of securities margin trading's underlying stocks is summarized in Table 1.

Table 1. Quantity of Stocks Underlying Securities Margin Trading

\begin{tabular}{lc}
\hline Time Period & Quantity \\
\hline $31^{\text {st }}$ March $2010-24^{\text {th }}$ November 2011 & 90 \\
\hline $25^{\text {th }}$ November $2011-15^{\text {th }}$ September 2013 & 278 \\
\hline $16^{\text {th }}$ September $2013-21^{\text {st }}$ September 2014 & 500 \\
\hline $22^{\text {nd }}$ September 2014 - Present & 900 \\
\hline
\end{tabular}

\section{Related Literature}

With regard to the effects of securities margin trading on stock market volatility, three of the viewpoints expressed in the literature are summarized below:

Some research argues that the launch of securities margin trading generally reduces stock price volatility and stabilizes the stock market. Hong and Stein (2003) introduced a heterogeneous agent model and conducted research on whether securities margin trading can prevent the stock price from decreasing. They found that the frequency of extreme values of the stock return rate would increase if securities margin trading were not allowed in the stock market. They concluded that the stock market would fluctuate sharply if it did not allow securities margin trading or 
at least set greater restrictions on it. Bai, Chang and Wang (2006) constructed a perfectly rational expectation equilibrium model and evaluated the impacts of short selling restrictions on market efficiency. Consequently, they noted that short selling restrictions can increase stock price volatility. Angel (1997) selected 114 stocks from New York Stock Exchange and analyzed the relation between stock price decline and short selling. The study concluded that securities margin trading makes the stock market, to some extent, more stable. Cai, Li and Xia (2006) investigated the Hong Kong stock market and utilized the critical incident method. They found that the degree of stock price fluctuation decreased when short selling was allowed.

In contrast, some other research argues that securities margin trading generally results in an increase in stock market volatility. Bogen and Krooss (1960) proposed the 'pyramid-pyramid upside-down effect' to explain why securities margin trading results in increased stock price volatility. The mechanism they proposed is as follows: (1) when the stock price increases, investors depend on margin trading to short buy stocks and enhance market demand. As a result, the stock price increases further. (2) When the stock price decreases, investors depend on securities lending to short sell stocks and enhance market supply, thus further decreasing the stock price. The theoretical model of Allen and Gale (1991) suggests that the market is in perfect competition and equilibrium, whereas it would be in imperfect competition if securities margin trading is allowed. Imperfect competition results in low market efficiency. Hence, they argue that securities margin trading has a negative impact on stock market volatility. Henry and McKenzie (2006) analyzed daily data from the Hong Kong stock market from 1992 to 2003 and found that allowing securities margin trading resulted in increased price volatility for certain stocks.

A third perspective regards securities margin trading as having no effect on stock market volatility. Based on theoretical analysis, Kraus and Rubin (2003) concluded that securities market volatility is affected by other external factors in the market, but is not caused by securities margin trading. Battalio and Schultz (2006) developed an empirical analysis of the high-frequency trading data of companies listed on the National Association of Securities Dealers Automated Quotations (NASDAQ) during 1999 and 2000. They found that stock price fluctuation has no significant correlation with securities margin trading. Gong (2010) used the time-series GARCH model to model stock market volatility and reported that securities margin trading has little impact on stock market volatility in the short term. Lee and Liu (2011) utilized a rank-sum test and the Granger causality test to develop an empirical analysis of data obtained from the Taiwan securities market. They concluded that stock market volatility undergoes no significant change due to scaling-up of securities margin trading. Tang (2012) utilized the Chinese CSI 300 Index and conducted vector autoregression (VAR), a co-integration test, and impulse response etc. on the sample data. Corresponding test results indicated that the impact of securities margin trading on stock market volatility was not significant as a whole, and that external factors, together with stock market inertia, are the primary reasons for stock price volatility.

These three viewpoints on the relation between securities margin trading and stock market volatility were primarily derived from quantitative research. As discussed above, different conclusions were drawn even when the same quantitative method was utilized to investigate different stock markets. Therefore, previous research results about other stock markets cannot be applied directly to the stock market of China. Besides, predominant quantitative research methods in the existing literature conduct either cross-sectional, horizontal comparison analyses or longitudinal, vertical comparison analyses. Cross-sectional analysis fails to consider other influential factors simultaneously, whereas time-series analysis ignores the influence of different countries or companies. Previous research on the effects of securities margin trading on stock market volatility could be flawed, as previous research may have omitted certain key explanatory variables. Consequently, this paper attempts to resolve the abovementioned problems by using the DID method to effectively evaluate securities margin trading in China, which was introduced only recently, in 2010.

\section{Research Methodology}

One reason why the CSRC introduced securities margin trading was to reduce volatility in China's A-share market. As introduced in Section 2, CSRC increased the number of underlying stocks on three occasions after securities margin trading was first introduced in 2010. These actions could indicate that the introduction of securities margin trading helped the CSRC achieve its objective. Therefore, this paper puts forth the following hypothesis: the introduction of securities margin trading in 2010 significantly decreased China's A-share market volatility.

Along with securities margin trading, a series of other factors also influence A-share market volatility in China, such as economic growth rate, international stock market volatility and the gold price (Zhang 2010). It is spurious to eliminate the impact of other influences on China's A-share market and effectively evaluate the impacts of securities margin trading using a simple Ordinary Least Square method (Lee \& Liu 2011). In addition, the introduction of 
securities margin trading in China can be observed as a natural experiment with which to test its effects on China's A-share market volatility. This is because, (1) original securities margin trading was limited to only 90 A-share stocks, which became the transaction targets, and (2) most other factors relevant to A-shares remained fixed to a large extent in the short term. In this natural experiment, shares affected by securities margin trading form a treatment group, whilst the unaffected shares comprise the control group. Imbens and Wooldridge (2007) indicated that the DID model can better control the systematic differences between the treatment group and the control group; thus, it is an effective model for evaluating change in the treatment group, giving an impetus to develop a DID analysis to investigate the effects of securities margin trading (introduced in 2010) on China's A-share price volatility.

When China launched securities margin trading in the A-share market in 2010, only 90 underlying stocks were selected: 50 from the SHSE and 40 from the SZSE. This paper chooses 50 underlying stocks from the SHSE as the treatment group. The control group is comprised of 50 non-underlying stocks from A-shares listed on the SHSE for at least 10 years (Table 2).

Table 2. Treatment Group and Control Group

\begin{tabular}{|c|c|c|}
\hline \multicolumn{3}{|c|}{ Stock Codes } \\
\hline Treatment group & $\begin{array}{l}600000 ; 600005 ; 600015 ; 600016 ; 600018 ; 600019 ; \\
600028 ; 600029 ; 600030 ; 600036 ; 600048 ; 600050 ; \\
600089 ; 600104 ; 600320 ; 600362 ; 600383 ; 600489 ; \\
600519 ; 600547 ; 600550 ; 600598 ; 600739 ; 600795 ; \\
600837 ; 600900 ; 601006 ; 601088 ; 601111 ; 601166 ; \\
601168 ; 601169 ; 601186 ; 601318 ; 601328 ; 601390 ; \\
601398 ; 601600 ; 601601 ; 601628 ; 601668 ; 601727 ; \\
601766 ; 601857 ; 601898 ; 601899 ; 601919 ; 601939 ; \\
601958 ; 601988 ;\end{array}$ & $\begin{array}{c}50 \text { underlying } \\
\text { stocks of securities } \\
\text { margin trading } \\
\text { from A-shares of } \\
\text { the SHSE }\end{array}$ \\
\hline Control group & $\begin{array}{c}600004 ; 600006 ; 600007 ; 600008 ; 600009 ; 600010 ; \\
600011 ; 600012 ; 600017 ; 600020 ; 600021 ; 600022 ; \\
600027 ; 600031 ; 600035 ; 600037 ; 600038 ; 600039 ; \\
600050 ; 600051 ; 600052 ; 600053 ; 600054 ; 600055 ; \\
600056 ; 600058 ; 600059 ; 600060 ; 600061 ; 600068 ; \\
600069 ; 600070 ; 600073 ; 600077 ; 600078 ; 600079 ; \\
600080 ; 600081 ; 600082 ; 600083 ; 600084 ; 600085 ; \\
600086 ; 600087 ; 600088 ; 600090 ; 600093 ; 600094 ; \\
600095 ; 600096 ;\end{array}$ & $\begin{array}{l}50 \text { non-underlying } \\
\text { stocks of securities } \\
\text { margin trading } \\
\text { from A-shares of } \\
\text { the SHSE }\end{array}$ \\
\hline
\end{tabular}

The share price is the result of three groups of factors, being macro environmental, industrial and corporate factors. The external macro environment faced by listed companies selected as members of either the treatment or control group is the same. A change in the industrial or corporate internal environments could reduce or increase the share price by affecting the shares' supply and demand. The turnover ratio refers to the percentage of stock holdings replaced by other holdings within a specific time and reflects the stock's marketability; therefore, it can be used to measure the shares' differences in supply and demand brought about by their differences in industrial and corporate environments. For this reason, this paper introduces turnover ratio as an independent variable in the DID model. Other independent variables include a time dummy variable and a category dummy variable. This paper chooses stock price volatility as the dependent variable. The DID model is of the following form:

$$
R_{i t}=\beta_{0}+\beta_{1} d u_{i t}+\beta_{2} d t_{i t}+\beta_{3} d u_{i t} d t_{i t}+\beta_{4} r_{i t}+\varepsilon_{i t}
$$

where $R_{i t}$, the price volatility of stock $i$ on date $t$, is calculated as follows:

$$
R_{i t}=\frac{p h_{i t}-p l_{i t}}{\frac{p h_{i t}+p l_{i t}}{2}}
$$

where $p h_{i t}$ and $p l_{i t}$ are the highest and lowest prices of stock $i$ on date $t$, respectively. The group dummy variable is $d u_{i t}$. If the stock is the underlying stock of securities margin trading, then $d u_{i t}$ is 1 . Otherwise, it is 0 . The time 
dummy variable is $d t_{i t}$. Before $31^{\text {st }}$ March 2010, $d t_{i t}$ is 0 ; afterwards, it is 1 . The control variable of the DID model is $r_{i t}$. It is the turnover rate of stock $i$ on date $t$.

According to the value of $d t_{i t}$, two groups of equations can be generated. As presented in Table 3 , the stock price volatilities, $R_{i t}$, of the treatment group are $\beta_{0}+\beta_{1}+\beta_{4} \mathrm{r}_{\mathrm{it}}+\xi_{\mathrm{it}}$ and $\beta_{0}+\beta_{1}+\beta_{2}+\beta_{3}+\beta_{4} \mathrm{r}_{\mathrm{it}}+\xi_{\mathrm{it}}$ before and after the introduction of securities margin trading, respectively. The stock price volatilities $R_{i t}$ of the control group are $\beta_{0}+\beta_{4} \mathrm{r}_{\mathrm{it}}+\xi_{\mathrm{it}}$ and $\beta_{0}+\beta_{2}+\beta_{4} \mathrm{r}_{\mathrm{it}}+\xi_{\mathrm{it}}$ before and after the introduction of securities margin trading, respectively. From these four equations, it is evident that estimating coefficient $\beta_{3}$ is the key to determining whether or not the introduction of securities margin trading reduces market volatility in China's A-shares. Therefore, this paper develops a regression analysis on the processed panel data to estimate the value of $\beta_{3}$ and, accordingly, verify the research hypothesis.

Table 3. The Mean Equations Gained from the DID Model

\begin{tabular}{lllc}
\hline & After $31^{\text {st }}$ March 2010 $(d t=1)$ & Before $31^{\text {st }}$ March 2010 $(d t=0)$ & \\
\hline $\begin{array}{l}\text { Treatment } \\
(d u=1)\end{array}$ & $\beta_{0}+\beta_{1}+\beta_{2}+\beta_{3}+\beta_{4} \mathrm{r}_{\text {it }}$ & $\beta_{0}+\beta_{1}+\beta_{4} \mathrm{r}_{\text {it }}$ & $\beta_{2}+\beta_{3}$ \\
\hline $\begin{array}{l}\text { Control } \\
(d u=0)\end{array}$ & $\beta_{0}+\beta_{2}+\beta_{4} \mathrm{r}_{\text {it }}$ & $\beta_{0}+\beta_{4} \mathrm{r}_{\text {it }}$ & $\beta_{2}$ \\
\hline & $\beta_{1}+\beta_{3}$ & $\beta_{1}$ & $\beta_{3}$ \\
\hline
\end{tabular}

\section{Data}

The sample observation interval selected for this paper covers 244 transaction dates before and after the introduction of securities margin trading in 2010. Strictly speaking, the period prior to its introduction was from $31^{\text {st }}$ March 2009 to $30^{\text {th }}$ March 2010 and the post-introduction period was from $31^{\text {st }}$ March 2010 to $31^{\text {st }}$ March 2011. The historical transaction data on the 50 underlying stocks and 50 non-underlying stocks, including daily highest price, daily lowest price, daily open price, daily close price and turnover rate, were obtained.

In order to reduce the impact of special events on price distributions, any stocks listed on the SHSE after 2005 or suspended from trading for over 20 transaction days during the sample interval were eliminated. The effective sample comprised 47 stocks in the treatment group and 46 in the control group.

\section{Empirical Results}

To understand the effects of implementing securities margin trading on China's A-share market volatility, this paper first compares sample data from A-shares in both the treatment group and the control group via descriptive analysis. Table 3 summarizes the following main findings: (1) the maximum values of the price volatility of China's A-shares decreased after $31^{\text {st }}$ March 2010 in both groups; (2) the average values of stock price volatility of both groups were lower than those from before $31^{\text {st }}$ March 2010; and (3) the standard deviations of both groups dropped after $31^{\text {st }}$ March 2010. All these figures substantiate the fact that China's A-share market volatility decreased after the introduction of securities margin trading in 2010. However, how significant was it? Was the decrease a consequence of introducing securities margin trading in 2010? These questions are answered by further DID analysis.

Table 4. Descriptive Analysis Results before and after $31^{\text {st }}$ March 2010

\begin{tabular}{ccccccccc}
\hline & \multicolumn{2}{c}{ Mean } & \multicolumn{2}{c}{ Min } & \multicolumn{2}{c}{ Max } & \multicolumn{2}{c}{ Std. Dev } \\
\cline { 2 - 9 } & Before & After & Before & After & Before & After & Before & After \\
\hline $\begin{array}{c}\text { Treatment } \\
\text { Group }\end{array}$ & .03607 & .0313525 & 0 & 0 & .247001 & .13918 & .0194621 & .0175074 \\
\hline $\begin{array}{c}\text { Control } \\
\text { Group }\end{array}$ & .04058 & .0373227 & 0 & 0 & .201139 & .184797 & .0211982 & .0199755 \\
\hline
\end{tabular}


By developing a random effects regression analysis on the processed panel data, the following results are obtained. As Table 5 shows, the coefficient of $d u d t$ is -0.0023471 at a significance level of $P<0.01$. Both figures indicate that the introduction of securities margin trading in 2010 had significant impacts on China's A-share market volatility and that, taken as a whole, volatility decreased significantly. These results support the hypothesis proposed in Section 4 that 'the introduction of securities margin trading in 2010 decreased China's A-share market volatility significantly’.

Table 5. Results of Regression Analysis on the Panel Data

\begin{tabular}{ccccccc}
\hline & Coef. & Std. Err. & $z$ & $P>|z|$ & \multicolumn{2}{c}{$[95 \%$ Conf. Interval] } \\
\hline$d u$ & -.0004553 & .0011341 & -0.40 & 0.688 & -.0026781 & .0017676 \\
\hline$d t$ & .0023017 & .0002237 & 10.29 & 0.000 & .0018634 & .0027401 \\
\hline$d u d t$ & -.0023471 & .0003072 & -7.64 & 0.000 & -.0029491 & -.0017451 \\
\hline$r$ & .0046229 & .0000404 & 114.36 & 0.000 & .0045437 & .0047021 \\
\hline${ }_{c}$ cons & .0266287 & .000815 & 32.67 & 0.000 & .0250313 & .0282262 \\
\hline
\end{tabular}

Empirical results show that the introduction of securities margin trading has been beneficial for the discovery of stocks' intrinsic value and brings the stock market more information. When the share price is significantly higher than its intrinsic value, rational investors perceive this change and take recourse to short selling in order to make the share price decrease and become reasonable. On the contrary, when the share price is significantly lower than its intrinsic value and undervalued by the market, rational investors borrow money from securities companies to buy the shares. Finally, the decrease in share price is prevented to some extent. Therefore, the introduction of securities margin trading is beneficial for the decrease of share price volatility and the stability of stock market.

\section{Conclusion}

Identifying the effects of the introduction of securities margin trading in 2010 on China's A-share market volatility has great significance in both theory and practice. There is no consensus on the relation between securities margin trading and stock market volatility in previous literature. Besides, previous research investigates other stock markets, which the stock market of China cannot readily refer to. Moreover, predominant quantitative research methods in the existing literature could be flawed, as previous research may have omitted certain key explanatory variables. The orderly opening-up of securities margin trading in China's A-share market created an informative natural experiment, allowing this paper to use a DID model to estimate the effects. This paper selects transaction data from 50 stocks underlying securities margin trading and 50 non-underlying ones from $31^{\text {st }}$ March 2009 to $31^{\text {st }}$ March 2011, and establishes a set of panel data that is analyzed by random effects regression analysis. The results indicate that the introduction of securities margin trading in 2010 significantly decreased China's A-share market volatility.

Although the launch of securities margin trading in 2010 brought about some positive effects on China's A-share market, it should be noted that the new securities business pose some problems. For example, asymmetry exists between margin trading and securities lending. It has been reported that the balance of securities lending was only $1.94 \%$ of the balance of margin trading until $31^{\text {st }}$ August 2012. This may be because there were not enough underlying shares for investors. Therefore, with reference to the conclusions above, this paper advances the following recommendations for Chinese securities market supervisory institutions. First, it should increase the number of underlying shares, and extend the capital supply for margin trading as well as the share supply for securities lending for the purposes of increasing securities margin trading market activity. Second, it should reduce the barriers and transaction costs of securities margin trading in order to encourage market acceptance of it and enhance its positive effects on China's A-share market.

\section{References}

Allen, F., \& Gale, D. (1991). Arbitrage Short Sales and Financial Innovation. Econometrica, 59, 1041-1068. https://doi.org/10.2307/2938173

Angel, J. (1997). Short Selling on the NYSE. Working Paper, Georgetown University.

Bai, Y., Chang, E., \& Wang, J. (2006). Asset Prices under Short-Sale Constraints. Working Paper, pp. 103-105. 
Bogen, J., \& Krooss, H. (1960). Security Credit and Its Economic Role and Regulation. Englewood Cliffs, Prentice-Hall, NJ.

Cai, J., Li, Y., \& Xia, L. (2006). Information Asymmetry and Short Sales Constraints: Evidence from the Hong Kong Stock Market. Working Paper. https://doi.org/10.2139/ssrn.979688

Gong, H. (2010). Research on the Effects of Securities Margin Trading on Stock Price Volatility - A Case Study of Hong Kong. Guangdong Business College, 29-35.

Harrison, H., \& Stein, J. (2003). Differences of Opinion, Short-Sales Constraints, and Market Crashes. Review of Financial Studies, 16, 487-525. https://doi.org/10.1093/rfs/hhg006

Henry, O., \& Kenzie, M. (2006). The Impact of Short Selling on the Price-Volume Relationship: Evidence from Hong Kong. Journal of Business, 2(79), 671-691. https://doi.org/10.1086/499135

Kraus, A., \& Rubin, A. (2003). The Effect of Short Sale Constraint Removal on Volatility in the Presence of Heterogeneous Beliefs. International Review of Finance, 4, 171-188. https://doi.org/10.1111/j.1468-2443.2005.00047.x

Lee, D., \& Liu, M. (2011). Does More Information in Stock Price Lead to Greater or Smaller Idiosyncratic Return Volatility. Journal of Banking \& Finance, 35, 1563-1580. https://doi.org/10.1016/j.jbankfin.2010.11.002

Robert, B., \& Schultz, P. (2006). Options and the Bubble. The Journal of Finance, 5, 2017-2102.

Shenzhen Stock Exchange n.d. Retrieved 22 October 2015, from http://www.szse.cn/main/en/Products/Trading/MarginTrading/

Tang, Y. (2012). VAR Model Analysis on the Relation between Chinese Stock Market and Securities Margin Trading. Finance and Economy, 9, 17-20.

Xu, H., \& Chen, X. (2012). Whether the Launch of Securities Margin Trading Enhances the Stock Pricing Efficiency? - Based on a DID Model. Management World, 5, 110-113.

Zhang, C. (2010). A Reexamination of the Causes of Time-Varying Stock Return Volatilities. Journal of Financial and Quantitative Analysis, 45(3), 663-684. https://doi.org/10.1017/S0022109010000232 